\title{
Interactions in MOOCs: The Hidden Part of the Iceberg
}



\begin{abstract}
Interactions that take place between MOOC users outside of discussion forums, and out of the reach of course designers, have received little attention from the scientific community despite their potential influence on learner retention. Based on an online survey, we found that MOOCs are often used as an activity among friends and family, and not exclusively in the academics or in the workplace. Interactions between course users may continue beyond of the boundaries of the course, and sometimes into other MOOCs. These various interactions include collaborative tasks, as well as tasks which should be performed individually, such as assessments. This work illustrates the mismatch that can appear between prescribed and actual tasks, and the potential importance of interactions between users, to address the isolation that contributes to low retention rates for online learners.
\end{abstract}

Keywords: MOOC, interactions, social networks, lifelong learning, completion rates 


\section{Introduction}

While Massive Open Online Courses (MOOCs) undoubtedly represent a form of distance education, they all share a common characteristic that makes them unique in the online learning ecosystem: registration is typically free (Daniel, 2012). This is in sharp contrast with traditional distance education, where peer interactions occur primarily between learners who have paid fees to an institution or a company. For a learner in a tuition-free course like a MOOC, it is easier to encourage relatives, friends, and colleagues to enroll in a course with them. It is then possible to either do the work collaboratively or simply discuss the content of the class. Such interactions between learners, which are likely to occur beyond course forums, has been discussed in MOOC literature (Veletsianos, Collier, \& Schneider, 2015). These interactions can greatly impact learner retention and course satisfaction, as was documented in research on the interactionist paradigm (Tinto, 1975; Thomas, 2000; Rovai, 2002, 2003).

Several qualitative studies have revealed the existence of interactions in MOOCs, beyond those that occur on course forums (Milligan \& Littlejohn, 2014; Veletsianos et al., 2015; Kellogg, Booth, \& Oliver, 2014). Most quantitative analyses of such interactions date back to the pioneering connectivist MOOCs (cMOOCs) of the late 2000s (Fini, 2009; Kop, 2011), and as such, there is a great lack of data regarding non-connectivist MOOCs, often labelled xMOOCs (Daniel, 2012). Because of the relative absence of quantitative data on these interactions, it is difficult to discern whether those observations of interactions occurring outside of the forums are anecdotal or rather reveal a widespread phenomenon. In this paper, we aim to provide such quantitative data through the analysis of 7,00o survey responses retrieved from students registered in 12 MOOCs organized through French universities.

The first question of the survey tried to assess the extent of the phenomenon. How common is interaction between learners outside of course forum boundaries? In our opinion, a study focused on such a question would provide little information. Indeed, it is assumed that a brief online chat between two friends regarding a course they both engage in does not have the same significance or impact on retention than a face-to-face collaboration on assignments between colleagues or family members. This leads to a second set of questions. Which types of learners are the most likely to interact outside of discussion forums on MOOC-related topics? Do these interactions mostly take place face-to-face or online? What is their purpose?

To show the lineage of such questions, we will first discuss the historical and theoretical aspects of the relationship between interactions and course retention (Tinto, 1975), and then present a selection of publications on interactions in MOOCs. The research presented here was inspired by the work of renowned researchers like Tinto $(1975,1982)$ who have pinpointed the influence of parameters, such as social integration, on retention. Social integration depends upon daily interactions, particularly with other students. Decades later, many authors still underpin its importance, in particular within the context of distance education (Fulford \& Zhang, 1993; Thomas, 2000; Rovai, 2002, 2003). This line of reasoning inspired our research questions. A few articles have aimed to identify the channels used by participants to interact with one another in the first generation of MOOCs, often labelled as connectivist (Fini, 2009; Kop, 2011; Koutropoulos et al., 2014), using a quantitative perspective. Due to the small number of registrants, surveys generally gathered only a few dozen answers and are no longer relevant since the phenomenon has grown since then.

After 2012, publications shifted from interactions in cMOOCs to interactions in xMOOCs, with an important focus on course forums (Gillani \& Eynon, 2014). Most work on interactions outside the 
course forums is qualitative: for example, Milligan and Littlejohn (2014) studied a MOOC on clinical research through a qualitative approach and discussed the use of MOOCs within professional networks; Veletsianos et al. (2015) focused on the experience of learners on social networks, and mentioned the existence of interactions about the MOOC within the family circle; Bulger, Bright, and Cobo (2015) analyzed 4,000 face-to-face events organized in 140 countries through meetup applications; Chen \& Chen (2015) focused on the interactions between students in a MOOC that was incorporated into course curriculum. While this qualitative research provides a glimpse into student interactions and a first basis for designing a survey, it is our opinion that a quantitative analysis should also be conducted to clarify how widely these interactions occur. In the following paragraphs, we explore the details of the design and methodology we followed to plan and implement the survey.

\section{Material and Methods}

\section{Design of the Survey Items}

Items used in this survey were designed based on a review of the literature on interactions in MOOCs. In addition to the usual questions on demographics and motivations to register (Appendix), we gathered three types of information:

1. The nature of the relationship among the learners, specifically distinguishing between the interactions that occurred among people who knew each other before the course, such as colleagues (Milligan \& Littlejohn, 2014) or family members (Veletsianos et al., 2015), and the interactions that occurred among learners who met through the MOOC.

2. The distinction between face-to-face meetings and online interactions in the MOOC, primarily focusing on the purpose of these interactions.

3. The number of MOOCs users' reported to have registered for and/or completed. A subset of the questions were tailored to specific respondents. For the main example, items related to the nature and modality of interactions were addressed only to the respondents who had interacted with a fellow learner outside of forums in a previous MOOC. For this subset of questions, only a few hundreds of responses were collected. Only a translation from French of the exact wording of the questions, as well as the corresponding possible answers, will be provided. In the following paragraphs, we will delve further into the methodology used for the distribution of the survey.

\section{Methodology of Delivery of the Survey}

In a MOOC, the proportion of registrants who answer a survey tends to decrease sharply after the first week of the course (Lamb, Smilack, Ho, \& Reich, 2015), which led us to ask the partners organizing the course to deliver the survey as early as possible. All of the surveys were therefore delivered during the first week of the course, which meant that the answers reflected either the participants' declared intentions to interact with others during the remaining weeks of the course, or on their past behaviors in previous courses. The debatable reliability of declared intentions drove us to focus on accounts of past interactions for a significant amount of items. 
The survey was sent to 11 MOOCs organized on FUN (France Université Numérique), and one MOOC organized on Canvas.net, between September 2015 and November 2015 (Table 1). It is important to note that for all the courses we studied, both the registration and certification were free. Most teams from French institutions whose MOOCs were launched during this period of time were contacted. All of those that agreed to deliver the survey were included in the study. The fact that most were organized on FUN, and only one on Canvas, reflects the predominance of FUN in the French MOOC ecosystem. We believe that the technological differences between these two Learning Management Systems have little impact on the interactions occurring outside of the boundaries of course forums.

Table 1

A Description of the MOOCs Included in This Study

\begin{tabular}{cccccc} 
Course ID & Course name & Platform & $\begin{array}{c}\text { \# of } \\
\text { answers }\end{array}$ & Launch date & End date \\
\hline ASSO & $\begin{array}{c}\text { Launching a Student } \\
\text { Association }\end{array}$ & FUN & 140 & $05 / 11 / 2015$ & $02 / 12 / 2015$ \\
CB & $\begin{array}{c}\text { Creative Box } \\
\text { CC }\end{array}$ & Canvas & 1392 & $28 / 09 / 2015$ & $28 / 10 / 2015$ \\
EDD & $\begin{array}{c}\text { Change: Mechanisms } \\
\text { and Stakes }\end{array}$ & FUN & 624 & $21 / 09 / 2015$ & $23 / 11 / 2015$ \\
ER & Renewable Energies & FUN & 1190 & $28 / 09 / 2015$ & $23 / 11 / 2015$ \\
FLE & French as a Foreign Language & FUN & 322 & $02 / 11 / 2015$ & $18 / 12 / 2015$ \\
MOOCAZ & Designing a MOOC from A to Z & FUN & 667 & $02 / 11 / 2015$ & $16 / 12 / 2015$ \\
MSD & Deformable Solids & FUN & 271 & $21 / 09 / 2015$ & $23 / 11 / 2015$ \\
PDM & Mechanical Sizing & FUN & 156 & $21 / 09 / 2015$ & $22 / 11 / 2015$ \\
PU & The Weight of the Universe & FUN & 561 & $14 / 09 / 2015$ & $19 / 10 / 2015$ \\
RMOOC & Introduction to Statistics with R & FUN & 499 & $14 / 09 / 2015$ & $25 / 10 / 2015$ \\
VP & Physical Volcanology & FUN & 982 & $05 / 10 / 2015$ & $30 / 11 / 2015$
\end{tabular}

${ }^{*}$ Note. $\mathrm{N}=7614$

A total of 7,614 answers were collected. The details of these courses and the number of answers per course are provided in Table 1. The analysis of sociodemographic data shows that in most courses, a majority of learners work full-time or part-time and have at least a Master's degree (Table 2) - a result consistent with published studies (Christensen et al., 2013; Seaton et al., 2014). We observed that 81\% of respondents declared that they live in France.

The survey was accessible as a Google Form embedded in a page on the first section of the course in an attempt to increase response rates. It is likely that the self-selection bias inherent to this type of survey may have induced an overrepresentation of learners particularly engaged in the course, and therefore the most likely to interact. As well, it is important to note that the interactions between learners outside of discussion forums may be less common in the courses than they appear in the survey. 
Table 2

Sociodemographic Data of Studied Courses

\begin{tabular}{|c|c|c|c|c|c|c|c|c|c|c|c|}
\hline Course &  & 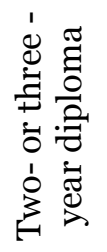 & 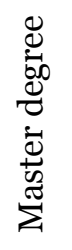 & $\stackrel{\varrho}{a}$ &  & 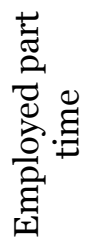 & 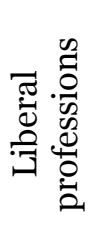 &  &  & 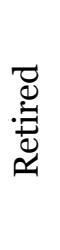 & $\frac{\dot{\Phi}}{\dot{0}}$ \\
\hline ASSO & 24 & 46 & 26 & 4 & 19 & 4 & 4 & 61 & 10 & o & 1 \\
\hline $\mathrm{CB}$ & 9 & 31 & 34 & 4 & 30 & 3 & 8 & 48 & 7 & 1 & 4 \\
\hline $\mathrm{CC}$ & 8 & 31 & 51 & 10 & 43 & 8 & 5 & 12 & 12 & 17 & 4 \\
\hline ER & 14 & 29 & 52 & 6 & 43 & 5 & 9 & 14 & 17 & 8 & 4 \\
\hline EDD & 10 & 34 & 50 & 6 & 41 & 8 & 7 & 13 & 19 & 6 & 6 \\
\hline FLE & 5 & 24 & 36 & 6 & 35 & 14 & 8 & 13 & 17 & 8 & 5 \\
\hline MOOCAZ & 10 & 44 & 58 & 14 & 58 & 9 & 14 & 5 & 9 & 2 & 4 \\
\hline MSD & 14 & 32 & 38 & 8 & 41 & 2 & 4 & 32 & 16 & 3 & 3 \\
\hline PDM & 6 & 37 & 50 & 7 & 44 & 3 & 6 & 14 & 22 & 6 & 5 \\
\hline $\mathrm{PU}$ & 3 & 18 & 44 & 10 & 48 & 6 & 7 & 8 & 7 & 22 & 3 \\
\hline RMOOC & 11 & 31 & 58 & 22 & 50 & 3 & 5 & 16 & 12 & 3 & 10 \\
\hline VP & 10 & 34 & 44 & 13 & 48 & 6 & 6 & 10 & 10 & 17 & 3 \\
\hline
\end{tabular}

${ }^{*}$ Note. $\mathrm{N}=7614$; H.E. (Higher Education)

The substantial number of answers $(n=7,614)$ regarding the context surrounding participants' registration in the MOOC enabled us to calculate an average and a standard error among the different variables that we surveyed (introduced by \pm in the text, which accounts for the variability between the 12 courses). For the subset of questions where we collected only a few hundred answers, results were described using a different approach. Percentages provided here were computed from pooled responses, and as a result, no standard errors will be provided.

\section{Results}

\section{Registering Alone or With Other People}

The questions that were asked of all respondents focused on two topics: collective registration and intent to complete the course. We first addressed the frequency of what we called "joint registrations," which corresponded to the fact that a learner registered for a course with another learner they already knew: "Have people you know (friends, colleagues, etc.) registered in this MOOC?" Three mutually exclusive answers were possible:

- $\quad 82 \%( \pm 13)$ answered "Not to my knowledge." 
- $\quad 7 \%( \pm 4)$ selected "Yes, but we do not intend to interact."

- $11 \%( \pm 6)$ chose the answer, "Yes, we intend to interact, whether it is to exchange information about the course, to motivate one another, or to perform activities together."

Most respondents appeared to follow the course on their own. Nevertheless, they may have unknowingly prompted some people to register in the course. If they did, it might generate interactions over the course later. We asked the question, "Have you recommended registering to the course to people you know?” Three non-mutually exclusive answers were possible:

- $\quad 56 \%( \pm 10)$ answered "No."

- $20 \%( \pm 7)$ answered "Yes, I have advised some friends or some family members to follow the course."

- $19 \%( \pm 7)$ responded "Yes, I recommended it to some colleagues (or classmates, in the case of students).”

- $4 \%( \pm 2)$ responded "Yes, I recommended it to both: some colleagues (or classmates, in the case of students), or friends and family members."

The proportion of learners who recommended the course was significantly higher than the proportion who registered with people they knew. We were also interested in assessing the extent to which respondents were encouraged to register in the course. We therefore asked the question, "Were you encouraged to register in the course?" Three mutually exclusive possibilities were proposed, one outlining the existence of a hierarchical relationship with the person who recommended the course:

- $85 \%( \pm 9)$ chose "Nobody encouraged me to register in the course."

- $7 \%( \pm 3)$ answered "A friend, a colleague (but not a superior), or an acquaintance encouraged me to register."

- $8 \%( \pm 9)$ answered "A superior, a teacher, or equivalent, encouraged me to register in the context of my work or my studies."

We found that only a small minority of learners were convinced to register to the course, which strengthens the argument that interactions are more likely to occur among users in the course forums, a hypothesis we will explore through the analysis of users' behaviors in past courses. To perform such an analysis, it is important to assess to what extent respondents had registered to courses prior to answering the survey. This allows us to target learners who could provide insights regarding past interactions that actually occurred, or interactions that could have potentially occurred.

We made a distinction between three non-mutually exclusive situations: a learner may have started a MOOC, completed a MOOC, or may be in the process of completing another MOOC. We added the requirement that respondents needed to have invested at least one hour into the course in order to claim they had started another MOOC. Similarly, a respondent claiming to have completed the course, whether it was free or not, as defined as having obtained a certificate of completion.

- $\quad 27 \%( \pm 18)$ of respondents declared "I have never started a MOOC." 
- Up to $20 \%( \pm 5)$ of them declared "I have started more than four MOOCs."

- Interestingly, only $50 \%( \pm 13)$ of respondents declared "I have never completed a MOOC."

As typically less than $10 \%$ of registrants obtain a MOOC completion certificate (Ho et al., 2014), it suggests that the respondents of the survey may not be representative of most registrants. We focused on this group of respondents who were new to MOOCs - which we will later call neophytes - in order to see whether there was a connection between registration and the pattern of interactions. The results suggest that even though most respondents had registered of their own initiative, they were much more likely to have been encouraged to register by a hierarchical superior/a teacher ( $28 \%$ of neophytes), or by friends, colleagues, or acquaintances (10\% of neophytes; Figure 1). This situation was in stark contrast with non-neophytes; only $7 \%$ of them had been encouraged to register to the course. Similarly, $26 \%$ of neophytes declared they wanted to interact with other learners, while only $6 \%$ of non-neophytes stated the same (Figure 1). Chi tests showed that these differences were highly significant (for incentive to register: $\mathrm{chi}=1220.5, \mathrm{df}=2, \mathrm{p}$-value $<2.10^{-16}$; for intention to interact: $\mathrm{chi}=526.19, \mathrm{df}=2, \mathrm{p}$-value $\left.<2.10^{-16}\right)$. These data suggest that word of mouth and top-down prompting play an important role in registration dynamics, and likely influence users' behaviors.


Figure 1. Differences in the interaction pattern between neophytes (who register to a MOOC for the first time) and non-neophytes. Left. Experience in MOOCs and incentives to register. Right. Experience in MOOCs and intention to interact. The exact wording of the questions and answers is provided in the text above.

Nevertheless, such data should be interpreted cautiously since it only represents declared intentions. To apprehend actual behavior, we focused on learners who already had registered to another MOOC before answering the survey $(\mathrm{N}=3350)$, beginning with the following question: "Have you interacted with a learner you knew ahead of the course in a previous MOOC?" The following answers were provided:

- $85 \%( \pm 6)$ answered "No, I never registered in a MOOC with anybody."

- $7 \%( \pm 5)$ chose "Someone I knew had registered in the course, but we did not interact." 
- $8 \%( \pm 3)$ picked "Someone I knew had registered in the course, and we did interact (discussions on the content of the course, collaboration over assignments, encouragements, etc.)."

An additional item was added to the survey in order to assess whether interactions outside of the boundaries of the course forums had occurred, and whether these interactions had gone on after the end of the course: "Have you interacted with a fellow learner outside of the boundaries of the course forums?" $(\mathrm{N}=3640)$. We specified that "fellow learners" did not include family members, friends, acquaintances, or colleagues. The analysis of the answers suggests that interactions beyond forums are uncommon, and that they do not last for long once the course is ended:

- $\quad 82 \%( \pm 5)$ answered “No, never."

- $13 \%( \pm 5)$ chose "Yes, but only during the course."

- $6 \%( \pm 2)$ replied "Yes, and we have kept interacting after the course."

In the following results, we intend to characterize these interactions. The corresponding questions were asked only to the respondents who had claimed they had interacted with a fellow learner. The various questions we have presented so far enable us to provide a quantitative perspective on the interactions among learners outside of the boundaries of the course forums. Even if they seem to concern only a minority of learners, they are far from being anecdotal and we need, at this point, to explore further the nature and purposes of such interactions.

\section{Nature of Relationships, Object, and Channel of Past Interactions}

In order to assess the nature of learner relationships with people they already knew in a course, we presented a question to gauge their level of prior interaction (Table 3). We proposed the following question: "If you followed a MOOC with someone you knew before the course, what was the nature of your relationship?" Choices were not mutually exclusive, since a learner could have interacted with different people, yet among the people who did identify a previous interaction, those people were primarily a "friend or acquaintance" (36\%), "family" member (41\%), or "colleague or classmate (for students)" (33\%). Only $3 \%$ answered that they had interacted with "a person (they) met in a previous MOOC." Family and friends seem to account for most of the interactions, while the proportion of people who met in previous MOOCs was negligible. The following questions aimed to identify the topic and the means of these interactions: "How did you interact?" and "Which communication means did you use?" (Table 3).

Unsurprisingly, face-to-face interactions seemed to prevail among learners who already knew each other ahead of the course, and virtual means of communication prevailed for learners who met during the course. Face-to-face gatherings with three or more participants appear to be uncommon without being negligible, since up to $17 \%$ of them declare they met up with people that they had pre-existing relationships with. This situation might be overrepresented among colleagues or classmates. We observed that $33 \%$ of learners who met in previous MOOCs engage together in activities, either individual or collective. This was slightly more frequent for friends, colleagues, or family. 
Table 3

Object and Channels Used for the Interactions Occurring Outside of the Boundaries of the Discussion Forum for MOOCs Followed Before Answering the Survey

People they knew People they met ahead of the course during the course

If you followed a MOOC with someone you met ahead of

$\mathrm{N}=339$

- Friend or acquaintance $36 \%$

- Family $41 \%$

- Colleague or classmate $33 \%$

- Someone met in a previous MOOC $3 \%$

\begin{tabular}{lcc}
\hline How did you interact? & $\mathrm{N}=339$ & $\mathrm{~N}=238$ \\
\hline - $\begin{array}{l}\text { We watched some videos together } \\
\text { (simultaneously). }\end{array}$ & $27 \%$ & $0 \%$ \\
- We helped each other in activities that were not & & $21 \%$ \\
$\begin{array}{l}\text { supposed to be collective (quizzes, assignments, } \\
\text { etc.). }\end{array}$ & $26 \%$ & $15 \%$ \\
- We did collective activities together. & $17 \%$ & $31 \%$ \\
- We encouraged each other to persist in the & $56 \%$ & $62 \%$ \\
course. & $70 \%$ &
\end{tabular}

\begin{tabular}{ccc}
\hline Which channel did you use? & $\mathrm{N}=339$ & $\mathrm{~N}=234$ \\
\hline - Virtual channels (social networks, email, etc.). & $36 \%$ & $52 \%$ \\
- We saw each other face-to-face. & $69 \%$ & $11 \%$ \\
- We saw each other face-to-face, in a group of 3 or & $17 \%$ & $3 \%$
\end{tabular}

These data suggest that two networks of interactions emerge during the MOOC, beyond the course forums. The first one corresponds to the immediate social circles of the learner. It is composed of friends, acquaintances, family, and colleagues, and is mostly made of one-on-one, face-to-face interactions. The other is virtual, composed of learners who meet for the first time in the MOOC, and is likely to originate in the course forums or the social networks associated with the course - Twitter threads, Facebook groups, etc. Those relationships might last a bit longer than the duration of the course, and for some learners, doing assignments together and becoming MOOC buddies. However, in the case of the French MOOCs, this rarely happens: less than 20 respondents developed such long-term relationships, out of the thousands that had completed a MOOC ahead of the survey.

\section{Discussion}

One of the main objectives of this paper was to provide a quantitative analysis of interactions in xMOOCs that had been almost exclusively subjected to qualitative research in previous studies (Milligan \& Littlejohn, 2014; Chen \& Chen, 2015; Veletsianos et al., 2015). In comparison to existing research, we were able to show that for most of the interactions, classmates or colleagues were not as much of a concern as family and friends or acquaintances. It was only in rare instances that previous MOOC interactions continued into another MOOC. Hence, it is unlikely that a large, hidden community of 
MOOC learners, formed within course forums, exists (in France at least). Though it is rare, it is not uncommon to create interactions during a class, yet it has been found that these have a short lifespan. Face-to-face, one-on-one interactions focus on exchanges on the course and on motivational prompts to complete it. Collaboration on activities or synchronous visualization of course content, which was the focus of Chen and Chen's (2015) work, seem to be marginal, even though non-negligible. The purpose of an important proportion of the interactions we studied was to complete course activities that were required to be carried out individually. Many certificates were obtained thanks to such interactions, a phenomenon that could possibly undermine the value of these free statements of successful completion.

In the following paragraphs, we will propose a hypothesis as to why people tend to interact with users they already know rather than new acquaintances from the course forums. The first element to factor in is the relative absence of obstacles to joint registrations. As mentioned in the introduction, the fact that those courses are free fosters the development of interactions with relatives, relations, or the workplace. Self-regulated learning readiness may also contribute to this phenomenon. Kizilcec, PérezSanagustín, and Maldonado (2017) have shown through large survey data and self-regulated learning scales that self-regulated learners were the most likely to complete the course. Moreover, numerous studies in distance education (Thomas, 2000; Rovai, 2002, 2003) have shown that the social integration of the learners is critical to their persistence in the course.

The association of these two ideas suggests that many learners could be self-regulated enough to understand that the absence of interactions in the course is likely to decrease their motivation to finish the MOOC. Some of them may therefore be trying to increase their social integration deliberately by enrolling colleagues or family members. The fact that one of the goals of the interactions was to encourage each other to persist in the course, corroborates this idea. Interacting with peers could be a strategy to compensate for the difficulty in interacting with faculty, but is made more difficult by the absence of dedicated features. In most xMOOCs, neither the discussion forums nor the design of the MOOCs are studied to foster collaborative learning (Margaryan, Bianco, \& Littlejohn, 2015; TovenLindsay, Rhoads, \& Lozano, 2015). It may therefore appear easier for learners to rely on already existing relationships rather than creating new ones.

This may explain why most learners try to enlist relatives, colleagues, friends, or acquaintances in the course, even if it rarely proves successful. The person that the learner encourages to join is likely dependent on their motivation to register for the course. We suggest that a learner will probably turn to colleagues when the MOOC is work-related, and to relatives, friends, or acquaintances in other cases. However, it is not possible to corroborate this trend based on the results of this survey, and further analyses are required to substantiate this statement.

Interestingly, it is common for learners to work as a group on tasks that are supposed to be carried out individually. We interpret this result to mean that many learners are disinterested in the certificate to demonstrate their own abilities, but instead view it as a means to increase their motivation to stay in the course. This observation corresponds to the Goal Commitment component of Tinto's (1975) retention model. Therefore, for these learners, collaboratively performing tasks that ought to be performed individually may not be considered as a form of cheating, since they may undermine the value to the certificate.

Since interactions outside the boundaries of the course appear to be uncommon, it is unlikely that they can provide enough social integration to make up for the lack of exchanges in the discussion forums. 
This hypothesis is strengthened by the fact that the respondents of the survey were significantly more engaged in the completion of MOOCs than most registrants, and were therefore more likely to have interacted with a fellow learner. Following an interactionist approach, which has survived to this day in the literature on attrition in distance education (Thomas, 2000; Rovai, 2002, 2003), we can surmise that the lack of interactions among learners, notably outside of the discussion forums, represents one of the main explanations for MOOCs' low completion rates.

\section{Conclusion}

One of the limitations of our research is that it provides little knowledge about what triggered the interactions we described, and what enabled some of them to persist after the end of the course. Instructional design and course topic are likely to have had a strong influence on such interactions, but the survey approach we followed could not provide that information. A content analysis of the interactions that commence in discussion forums and continue afterwards, following Gillani and Eynon's (2014) work, could prove an interesting approach to deepen our understanding of this issue. One other limitation of our work is that we had to extensively rely on behavior in past MOOCs because launching a survey at the end of a MOOC would have elicited too few responses. Nevertheless, there is no simple way to avoid this methodological issue, given low completion rates.

Compared to traditional fee-based distance education, MOOCs have at least two characteristics that foster the implementation of interactions outside of the course forums. Firstly, registration is free. Secondly, the level of prerequisites for the course is generally low, since course designers often downgrade the difficulty level of the courses given to on-campus students so as to meet the expected MOOC audience's requirements (Najafi, Rolheiser, Harrison, \& Håklev, 2015). Therefore, the certificates or statements of completion are usually designed to be within the reach of neophytes and are often not worthy of credentials in the eyes of the designers (Kolowich, 2013). The conjunction of these characteristics provides an interesting opportunity to foster collaborations within a learner's social circles, and therefore to fulfill one of the promises the pioneering MOOCs of the late 2000s held so high (Bell, 2011; Kop, Fournier, \& Mak, 2011), increasing the quality and the quantity of interactions among learners. This dimension of learners' experience needs to be improved if MOOCs are to be more than a mere variation on free online videos with the addition of discussion forums - research surely has a role to play in such an endeavor. 


\section{References}

Bell, F. (2011). Connectivism: Its place in theory-informed research and innovation in technologyenabled learning. The International Review of Research in Open and Distance Learning, 12(3), 98-118. http://dx.doi.org/10.19173/irrodl.v12i3.902

Bulger, M., Bright, J., \& Cobo, C. (2015). The real component of virtual learning: motivations for faceto-face MOOC meetings in developing and industrialized countries. Information, Communication \& Society, 18(10), 1200-1216. Retrieved from http://papers.ssrn.com/abstract $=2641798$

Chen, Y.-H., \& Chen, P.-J. (2015). MOOC study group: Facilitation strategies, influential factors, and student perceived gains. Computers \& Education, 86, 55-70. https://doi.org/10.1016/j.compedu.2015.03.008

Christensen, G., Steinmetz, A., Alcorn, B., Bennett, A., Woods, D., \& Emanuel, E. (2013). The MOOC phenomenon: Who takes massive open online courses and why? Retrieved from http://papers.ssrn.com/sol3/papers.cfm?abstract id=2350964

Daniel, J. (2012). Making sense of MOOCs: Musings in a maze of myth, paradox and possibility. Journal of Interactive Media in Education, 3. https://doi.org/10.5334/2012-18

Fini, A. (2009). The technological dimension of a massive open online course: The case of the CCKo8 course tools. The International Review of Research in Open and Distance Learning, 1O(5). http://dx.doi.org/10.19173/irrodl.v10i5.643

Fulford, C. P., \& Zhang, S. (1993). Perceptions of interaction: The critical predictor in distance education. American Journal of Distance Education, 7(3), 8-21. https://doi.org/10.1080/08923649309526830

Gillani, N., \& Eynon, R. (2014). Communication patterns in massively open online courses. The Internet and Higher Education, 23, 18-26. https://doi.org/10.1016/j.iheduc.2014.05.004

Kellogg, S., Booth, S., \& Oliver, K. (2014). A social network perspective on peer supported learning in MOOCs for educators. International Review of Research in Open and Distance Learning, 15(5), 263-289. http://dx.doi.org/10.19173/irrodl.v15i5.1852

Kizilcec, R. F., Pérez-Sanagustín, M., \& Maldonado, J. J. (2017). Self-regulated learning strategies predict learner behavior and goal attainment in massive open online courses. Computers \& Education, 104 (Supplement C), 18-33. https://doi.org/10.1016/j.compedu.2016.10.001

Koller, D., Ng, A., Do, C., \& Chen, Z. (2013). Retention and intention in massive open online courses. EDUCAUSE Review. Retrieved from http://er.educause.edu/articles/2013/6/retention-andintention-in-massive-open-online-courses

Kolowich, S. (2013). The professors behind the MOOC hype [Blog post]. Chronicle of Higher Education. Retrieved from http://chronicle.com/article/The-Professors-Behind-theMOOC/137905/ 
Kop, R. (2011). The challenges to connectivist learning on open online networks: Learning experiences during a massive open online course. The International Review of Research in Open and Distance Learning, 12(3), 19-38. http://dx.doi.org/10.19173/irrodl.v12i3.882

Kop, R., Fournier, H., \& Mak, J. S. F. (2011). A pedagogy of abundance or a pedagogy to support human beings? Participant support on massive open online courses. The International Review of Research in Open and Distance Learning, 12(7), 74-93. http://dx.doi.org/10.19173/irrodl.v12i7.1041

Koutropoulos, A., Abajian, S., deWaard, I., Hogue, R., Keskin, N., \& Rodriguez, C. (2014). What tweets tell us about MOOC participation. International Journal of Emerging Technologies in Learning (iJET), 9(1), 8-21. Retrieved from http://www.editlib.org/p/130546/

Lamb, A., Smilack, J., Ho, A., \& Reich, J. (2015). Addressing common analytic challenges to randomized experiments in MOOCs: Attrition and zero-inflation. In Proceedings of the Second (2015) ACM Conference on Learning @ Scale (pp. 21-30). New York, NY, USA: ACM. https://doi.org/10.1145/2724660.2724669

Margaryan, A., Bianco, M., \& Littlejohn, A. (2015). Instructional quality of massive open online courses (MOOCs). Computers \& Education, 8o, 77-83.

https://doi.org/10.1016/j.compedu.2014.08.005

Milligan, C., \& Littlejohn, A. (2014). Supporting professional learning in a massive open online course. International Review of Research in Open and Distance Learning, 15(5), 197-213. http://dx.doi.org/10.19173/irrodl.v15i5.1855

Najafi, H., Rolheiser, C., Harrison, L., \& Håklev, S. (2015). University of Toronto instructors' experiences with developing MOOCs. The International Review of Research in Open and Distributed Learning, 16(3). http://dx.doi.org/10.19173/irrodl.v16i3.2073

Rovai, A. P. (2002). Building sense of community at a distance. The International Review of Research in Open and Distributed Learning, 3(1). http://dx.doi.org/10.19173/irrodl.v3i1.79

Rovai, A. P. (2003). In search of higher persistance rates in distance education online programs. Internet and Higher Education, 6(1), 1-16. https://doi.org/10.1016/S1096-7516(02)00158-6

Seaton, D. T., Bergner, Y., Chuang, I., Mitros, P., \& Pritchard, D. E. (2014). Who does what in a massive open online course? Communications of the ACM, 57(4), 58-65.

Thomas, S. L. (2000). Ties that bind: A social network approach to understanding student integration and persistence. The Journal of Higher Education, 71(5), 591-615.

https://doi.org/10.2307/2649261

Tinto, V. (1975). Dropout from higher education: A theoretical synthesis of recent research. Review of Educational Research, 45(1), 89-125. https://doi.org/10.3102/00346543045001089

Tinto, V. (1982). Limits of theory and practice in student attrition. The Journal of Higher Education, 53(6), 687-700. https://doi.org/10.2307/1981525 
Toven-Lindsey, B., Rhoads, R. A., \& Lozano, J. B. (2015). Virtually unlimited classrooms: Pedagogical practices in massive open online courses. The Internet and Higher Education, 24, 1-12. https://doi.org/10.1016/j.iheduc.2014.07.001

Veletsianos, G., Collier, A., \& Schneider, E. (2015). Digging deeper into learners' experiences in MOOCs: Participation in social networks outside of MOOCs, notetaking and contexts surrounding content consumption. British Journal of Educational Technology, 46(3), 570587. https://doi.org/10.1111/bjet.12297 


\section{Appendix}

\section{Questions of the Survey Used in This Study}

What is your gender?

What is the highest diploma you have got?

What is your current professional status?

What is your nationality?

In which country do you leave?

How old are you?

What was your main motivation to register to the course?

To what extent are you interested in obtaining the course certificate?

Have people you know (friends, colleagues, etc.) registered in this MOOC?

Have you recommended registering to this course to people you know?

Were you encouraged to register in the course?

Have you ever started another MOOC aside of this one?

Have you interacted with a learner you knew ahead of the course in a previous MOOC?

Have you interacted with a fellow learner outside of the boundaries of the course forums?

If you followed a MOOC with someone you knew before the course, what was the nature of your relationship?

How did you interact?

Which communication means did you use? 